\title{
Adaptation of Real-Time PCR Assay for Specific Detection of Apple Proliferation Phytoplasma
}

M. Aldaghi ${ }^{1,2}$, S. Massart ${ }^{1}$, S. Roussel ${ }^{1}$, O. Dutrecq ${ }^{1}$ and M.H. Jijakli ${ }^{1}$

${ }^{1}$ Phytopathology department, University of Agronomic Sciences, Passage des déportés 2, 5030 Gembloux, Belgium

2 Plant diseases research department, Plant Pests \& Diseases Research Institute, P.O. Box 19395-1454, Tehran, Iran

Keywords: apple proliferation, phytoplasma, real-time PCR, detection, diagnostic

\begin{abstract}
Phytoplasmas are cell wall-less bacteria. Apple proliferation phytoplasma causes an important apple tree disease occurring in many apple-growing areas. Infected trees present symptoms such as witches' brooms, enlarged stipules and small sized fruits with incomplete coloration. The goal of this study was to develop a real-time PCR assay for specific detection of AP phytoplasma. In the literature, the detection of phytoplasmas by real-time PCR has already been done through the use of SYBR Green, TaqMan probes and TaqMan MGB probes. To ensure a double level of specificity (primers and probe), the use of probes was privileged. A key factor of real-time PCR is the selection of an appropriate threshold. Two methods are commonly used to set the threshold: (i) threshold $=10 \times \mathrm{XD}$, (ii) point of inflexion. A previously designed MGB probe (qAP-16S) was tested on our phytoplasmas collection (mainly AP, PD and ESFY). Using this probe, late fluorescent curves were obtained from ESFY isolates. These curves crossed the threshold calculated as $10 \times$ SD. So, a sequence alignment was made using database sequences and our sequencing results. A new MGB probe was designed in a region presenting a single nucleotide polymorphism (SNP) between AP and ESFY isolates. Using this probe, a specific detection of AP was obtained whatever the method of threshold calculation. No late amplification was observed with other phytoplasmas. Moreover, the amplification of serial dilutions of initial template DNA showed that this method is at least 16 and 8 times more sensitive than conventional PCR with specific (AP5/AP4) and polyvalent (qAP-16S-F/R) primers, respectively. In addition, the phytoplasma infection on inoculated apple tress was sooner detectable using this new probe in real-time PCR than by conventional PCR or biological indexing. So, the optimization of an existing method led to a quick, specific and sensitive method for detection of AP.
\end{abstract}

\section{INTRODUCTION}

As Apple proliferation (AP) phytoplasma is present in the list of A2 pests (Smith et al., 1992), apple plants destinated to the fruit grower have to be AP-free. So, the accurate and rapid detection of phytoplasma is a major prerequisite to control the disease and to fulfil the certification requirements. AP phytoplasma belongs to the Apple Proliferation group, which includes the Pear Decline (PD) and European Stone Fruit Yellows (ESFY) phytoplasmas (Loi et al., 1995; Seemuller et al., 1998; Frisinghelli et al., 2000). Tedeschi et al. (2002) and Jarausch et al. (2003) reported that the psyllid Cacopsylla melanoneura and $C$. picta (synonym $C$. costalis) are vectors of apple proliferation in Italy and in Germany, respectively.

AP phytoplasma is found in low concentration in sieve elements. It also presents an uneven distribution in plants and can not be cultured in vitro (Lee et al., 2000). The development of PCR method has offered new tools to diagnose these pathogens. So far, several specific or universal primer pairs have been designed to detect the 3 AP phytoplasma strains: AP, AT1 and AT2 (Ahrens and Seemuller, 1992; Lee et al., 1998, 1993; Lorenz et al., 1995; Schneider et al., 1997, Jarausch et al., 2000).

The real-time PCR system is based on the detection of a fluorescent reporter 
(Livak, 1995). The advantages of real-time PCR for detection compared to conventional methods are its high specificity, its enhanced sensitivity, its suitability to high throughput and quick analysis (Baric and Dalla-Via, 2004). A fixed fluorescence threshold is set by the operator significantly above the baseline. The scientists use two different ways for setting the threshold. Some refer to calculate the threshold by a formula $(10 \mathrm{x}$ Standard Deviation of the fluorescence values during the initial cycles). Others set it in the point of inflexion of fluorescence curve.

Real-time PCR has been already used to detect specifically AP phytoplasma through a MGB probe (Baric and Dalla-Via, 2004), to detect and quantify simultaneously 3 phytoplasma species through SYBR Green (Torres et al., 2005) and to detect and quantify AP phytoplasma using SYBR Green (Jarausch et al., 2004).

The aim of the present study was to improve and to optimize a real-time PCR method through the design and validation of a new TaqMan MGB probe.

\section{MATERIAL AND METHODS}

\section{Phytoplasma Isolates and Plant Material}

The phytoplasma isolates, their original host plants and their geographical origins are listed in Table 1. The isolates of AP, PD and ESFY were received as periwinkle [Catharanthus roseus (L.) G. Don] infected plants. They were maintained by periodic grafting on periwinkle. The isolates of AP obtained on apple plant materials were grafted on apple trees (variety: MM106) in an insect-proof greenhouse.

\section{Phytoplasma DNA Extraction}

The method described by Zhang et al. (1998) was applied with slight modifications for DNA extraction from healthy and infected plant materials.

\section{Detection of Phytoplasma by PCR Amplification}

PCR amplification was carried out in a volume of $25 \mu$ l containing: $0.2 \mathrm{mM}$ dNTP, $0.4 \mu \mathrm{M}$ of each primer (Eurogentec, Liege, Belgium), 1x PCR buffer (Eurogentec), $2 \mathrm{mM} \mathrm{MgCl} 2,0.5 \mathrm{U}$ of HotGoldStar DNA polymerase (Eurogentec) and 10-100 ng of template DNA. The primer pairs used in this work are listed in Table 2. PCR products were subjected to electrophoresis on 1.5 or $2 \%$ agarose gel and revealed with ethidium bromide under UV illumination.

\section{Oligonucleotide Design}

The qAP-16S-F/R primers and the qAP-16S TaqMan MGB probe were designed by Baric and Dalla-Via (2004). A new TaqMan MGB probe was designed using the 'primer Express' software version 5.0 (Applied Biosystems, Forster City, USA). The design of this new probe was based on our sequences (isolates AT1 and AP15) and the sequence alignments of the 16S rRNA gene of AP, PD and ESFY isolates from the database. The sequencing reaction of our cloned PCR products was performed with automated sequencer at GATC Biotech (Konstanz, Germany).

\section{Detection of Phytoplasma by Real-Time PCR}

The reactions were carried out on the GeneAmp 5700 Sequence Detection System (Applied Biosystems) in a total volume of $25 \mu 1$ containing 10-100 ng of template DNA, 1x qPCR Master Mix (Eurogentec) with dUTP, $400 \mathrm{nM}$ of each primer and $200 \mathrm{nM}$ of the probe. The thermal cycle consisted in $2 \mathrm{~min}$ at $50^{\circ} \mathrm{C}$ (carry-over inactivation), $10 \mathrm{~min}$ at $95^{\circ} \mathrm{C}$ (HotGoldStar DNA activation), followed by 40 cycles of $15 \mathrm{~s}$ at $95^{\circ} \mathrm{C}$ and $60 \mathrm{~s}$ at 60,62 or $64^{\circ} \mathrm{C}$. Each reaction included at least one blank without template and one negative control corresponding to a healthy plant. All the samples and controls were amplified in triplicate. Threshold levels were set to intersect the amplification curve according to two recommended methods: (i) threshold $=10 \times$ Standard Deviation (SD) of the fluorescence values during $5-15^{\text {th }}$ cycle, (ii) point of inflexion of fluorescence curve. 
The PCR efficiency was calculated by using the value of the linear regression slope (S) in the equation: \% PCR efficiency $=100 \times\left(10^{(1 /-S)}\right)-1$ (Ginzinger, 2002).

\section{Specificity and Limit of Detection}

To test the specificity of our real-time PCR protocol, DNA extracts containing other European fruit tree phytoplasma isolates (two PD and four ESFY) were amplified. The limit of detection of our real-time PCR method was compared to those of conventional PCR with primer pairs qAP-16S-F/R and AP5/AP4 (Jarausch et al., 1994) by preparing a serial dilution of DNA samples.

\section{RESULTS}

\section{Graft Inoculation and Biological Indexing}

Three months after grafting, the symptoms of phytoplasma disease were clearly evident on periwinkle plants. The strong reduction of the flower size as specific symptom of PD-infected plants was observed, whereas the size of flowers on periwinkles infected by ESFY was slightly affected.

After graft transmission to MM106 apple seedling rootstocks (four plants per sample), the appearance of preliminary symptoms of AP phytoplasmas on a few plants was observed 4 months after grafting in greenhouse. After 7 months, $75 \%$ of the apple trees presented AP symptoms of phytoplasma infection.

\section{PCR Amplification for AP Detection}

The results of biological indexing were confirmed using universal primer pairs fU5/rU3 (Lorenz et al., 1995) and F2n/R2 (Gundersen and Lee, 1996) on periwinkles (by 2 or 3 months) and apples (by 2 or 4 months). Phytoplasma DNA extracted of each apple tree was subjected to classical PCR. Fifty and ninety-six percent of periwinkle were PCRpositive after 2 and 3 months, respectively. Thirty-five and ninety percent of inoculated apple trees were positive after 2 and 4 months, respectively.

\section{Optimization of a Real-Time PCR Protocol}

The PCR conditions designed by Baric and Della-Via (2004) allowed the detection of all our strains (Table 1) from all subtypes of Apple Proliferation phytoplasma. No amplification products were obtained from healthy plants (apple and periwinkle). Nevertheless, there was a considerable fluorescent signal for ESFY and PD (whereas qAP-16S probe has been designed specifically for AP phytoplasma). This fluorescent signal crossed our threshold line, corresponding 10 x SD (data not shown). Also, the amplification curves of ESFY samples were completely sigmoid like AP samples. It seems Baric and Dalla-Via (2004) selected the threshold line according to the inflexion point. Moreover, all EFSY isolates used in this study have only one mismatch with the sequence alignment of qAP-16S probe (nucleotide at position 36 in Figure 1) whereas those of Baric and Dalla-Via had two mismatches. A positive signal was still observed for ESFY samples with the hybridization temperature of 62 or $64^{\circ} \mathrm{C}$, but the curves were not completely sigmoid (Fig. 2). Therefore, a new TaqMan MGB probe was designed for a better framing of the mismatch situate in $1 / 3$ middle part of probe (Fig. 1). The probe differed by one or two mismatches from the sequences of ESFY strains, by minimum three mismatches from that of PD or other more distinct phytoplasmas and by seven mismatches from that of healthy plants. With this new TaqMan MGB probe (namely AP-MGB) and a hybridization temperature of $64^{\circ} \mathrm{C}$, a specific detection of all the tested AP phytoplasma was achieved whatever the methodology to select the threshold (Fig. 2).

\section{Specific Detection of AP by Real-Time PCR}

The real-time PCR protocol was also applied to detect phytoplasma infection on grafted periwinkles and apple trees. Phytoplasma infection was confirmed in 71 and 
$100 \%$ of periwinkle samples by 2 and 3 months after grafting, respectively. Moreover, in the same sampling periods 70 and $100 \%$ of apple tress were positive. So, the phytoplasma infection after grafting was sooner detectable using this new probe in real-time PCR than by conventional PCR or appearance of symptoms on periwinkles and apple trees.

\section{Limit of Detection by Real-Time PCR versus Conventional PCR}

Real-time PCR yielded amplification products for the complete serial dilution of initial template DNA (including the 160,000-fold dilution corresponding to $0.625 \mathrm{pg}$ of DNA/PCR). Its limit of detection was 8 to 16 times lower than those of classical PCR using qAP-16S-F/R (up to 20,000-fold corresponding to $5 \mathrm{pg}$ of DNA /PCR) and AP5/AP4 (up to 10,000-fold corresponding to $10 \mathrm{pg}$ of DNA/PCR) primer pairs, respectively. The PCR efficiency for AP-MGB probe in real-time PCR was 98\%.

\section{DISCUSSION}

In this study, we applied biological indexing and molecular protocols to detect AP phytoplasma in apple and periwinkle.

The most commonly applied detection methods of AP phytoplasma by PCR targets unique sequences in the highly conserved $16 \mathrm{~S}$ rRNA gene to assure amplification of all AP strains (Jarausch et al., 2000; Kison et al., 1994). The conserved nature of the phytoplasmal 16Sr DNA hamper the design of oligonucleotide primers specific for AP phytoplasma without amplifying the closely related PD and ESFY phytoplasmas (Lorenz et al., 1995; Seemuller et al., 1998). This problem was overcome with real-time PCR using a primer pair and a fluorogenic probe.

Our experiments showed that the real-time PCR had a lower limit of detection than two previously published conventional PCR protocols. Moreover, the presence of phytoplasma infection was detected sooner with real-time PCR protocol than conventional PCR or biological indexing. These properties are very remarkable considering the importance of precise and rapid detection of quarantine organisms in control management programs.

In our results, the qAP-16S probe was not completely specific for AP detection in real-time PCR. ESFY isolates were also detected by this probe. It is probably due to the presence of only one mismatch between ESFY sequence and probe. Besides, it seems Baric and Dalla-Via set the threshold line on inflexion point while we set a threshold line corresponding to $10 \mathrm{x}$ S.D. The $10 \mathrm{x}$ S.D. is more popular than inflexion point method to set the threshold line (Ginzinger, 2002). Moreover, it is generally recommended to use a threshold line close to the baseline. Indeed, fluorescent curves may diverge at higher fluorescent level while lower thresholds will minimize the error due to small changes in efficiency (Hunt, 2005). Fitting the intersecting line upon the ten-times value of ground fluorescence standard deviation can be easily automated and is very robust (Pfaffl, 2003).

The place of mismatch on the probe has an important role on specificity. In our research, qAP-16S and AP-MGB probes have a single mismatch versus our ESFY isolate sequences in $1 / 3$ external and middle part of their sequences, respectively. During our experiments, the AP-MGB probe showed a higher specificity to AP phytoplasma than qAP-16S probe. This observation was in accordance with the previous reports on the specific detection of fruit tree viruses. These authors (Salmon et al., 2002; Marbot et al., 2002) detected specifically virus species when the single mismatch was located in the middle of the probe. If the TaqMan (or TaqMan MGB) probe is designed for allelic discrimination, the position of the polymorphic site (mismatch) should be approximately in the middle third of the sequence (Keck, 2005).

As summarized, a real-time PCR technique for specific detection of AP phytoplasma was developed. This method combined to an appropriate sampling procedure could be used in certification programs to ensure the release of AP-free plants. Further investigations will be focused on the development of a quantitative real-time PCR protocol able to monitor specifically AP phytoplasma populations on trees and orchards. 


\section{Literature Cited}

Ahrens, U. and Seemuller, E. 1992. Detection of DNA of plant pathogenic mycoplasmalike organisms by a polymerase chain reaction that amplifies a sequence of the 16S rRNA gene. Phytopathol. 82:828-832.

Baric, S. and Dalla-Via, J. 2004. A new approach to apple proliferation detection: a highly sensitive real-time PCR assay. J. Microbiol. Methods 57:135-145.

Frisinghelli, C., Delaiti, L., Grando, M.S., Forti, D. and Vindimian, M.E. 2000. Cacopsylla costalis (Flor 1861), as a vector of apple proliferation in Trentino. J. Phytopathol. 148:425-431.

Ginzinger, D.G. 2002. Gene quantification using real-time quantitative PCR: an emerging technology hits the mainstream. Experimental Hematol. 30:503-512.

Gundersen, D.E. and Lee, I.M. 1996. Ultrasensitive detection of phytoplasmas by nested PCR assays using two universal primer pairs. Phytopathol. Mediterr. 35:144-151.

Hunt, M. 2005. Real-time PCR. Accessed February 2006 at http://pathmicro.med.sc.edu/pcr realtime-home.htm

Jarausch, W., Peccerella, T., Schwind, N., Jarausch, B. and Krczal, G. 2004. Establishment of a quantitative real-time PCR assay for the quantification of apple proliferation phytoplasmas in plants and insects. Acta Hort. 657:415-420.

Jarausch, W., Saillard, C., Dosba, F. and Bove', J.M. 1994. Differentiation of mycoplasma-like organisms (MLOs) in European fruit trees by PCR using specific primers derived from the sequence of a chromosomal fragment of the apple proliferation MLO. Appl. Environm. Microbiol. 60:2916-2923.

Jarausch, W., Saillard, C., Helliot, B., Garnier, M. and Dosba, F. 2000. Genetic variability of apple proliferation phytoplasmas as determined by PCR-RFLP and sequencing of a non-ribosomal fragment. Mol. Cell. Probes 14:17-24.

Jarausch, B., Schwind, N., Jarausch, W. and Krczal, G. 2003. First report of Cacopsylla picta as a vector of apple proliferation phytoplasma in Germany. Plant Dis. 87:101.

Keck, W.M. 2005. Guidelines for designing primers and probes using Primer Express. Accessed February 2006 at http://keck.med.yale.edu/affymetrix/rtpcr/design.htm

Kison, H., Schneider, B. and Seemuller, E. 1994. Restriction fragment length polymorphisms within the apple proliferation mycoplasmalike organism. J. Phytopathol. 141:395-401.

Lee, I.M., Davis, R.E. and Gundersen-Rindal D.E. 2000. Phytoplasma: phytopathogenic mollicutes. Annu. Rev. Microbiol. 54:221-255.

Lee, I.M., Gundersen-Rindal, D.E., Davis, R.E. and Bartoszyk, 1.M. 1998. Revised classification scheme of phytoplasmas based on RFLP analyses of 16SrRNA and ribosomal protein gene sequences. Int. J. Syst. Bacteriol. 48:1153-1169.

Lee, I.M., Hammond, R.W., Davis, R.E. and Gundersen, D.E. 1993. Universal amplification and analysis of pathogen 16S rDNA for classification and identification of mycoplasmalike organisms. Phytopathol. 83:834-842.

Livak, K.J., Flood, S.J., Marmaro, J., Giusti, W. and Deetz, K. 1995. Oligonucleotides with fluorescent dyes at opposite ends provide a quenched probe system useful for detecting PCR product and nucleic acid hybridization. PCR Methods Appl. 4:357362.

Loi, N., Carraro, L., Musetti, R., Pertot, I. and Osler, R. 1995. Dodder transmission of two different MLOs from plum trees affected by 'leptonecrosis'. Acta Hort. 386:465470.

Lorenz, K.H., Schneider, B., Ahrens, U. and Seemuller, E. 1995. Detection of the apple proliferation and pear decline phytoplasmas by PCR amplification of ribosomal and nonribosomal DNA. Phytopathol. 85:771-776.

Marbot, S., Kummert, J., Salmon, M., Vendrame, M., Huwaert, A., Dutrecq, O. and Lepoivre, P. 2002. Development of RT-PCR tests for the routine detection of latent and ILAR viruses in fruit trees. Plant Protection Science 38:21-23.

Pfaffl, M.W. 2003. Quantitative mRNA Analytics in Molecular Endocrinology and Physiology. Accessed at February 2006 at http://www.gene-quantification.de/ 
habilitation.html

Salmon, M.A., Vendrame, M., Kummert, J. and Lepoivre, P. 2002. Rapid and homogenuous detection of Apple stem pitting virus by RT-PCR and a fluorogenic 3' minor groove binder-DNA probe. Eur. J. Plant Pathol. 108:755-762.

Schneider, B., Gibb, K.S. and Seemuller E. 1997. Sequence and RFLP analysis of the elongation factor $T h$ gene used in differentiation and classification of phytoplasmas. Microbiol. 143:3381-3389.

Seemuller, E., Kison, H., Lorenz, K.H., Schneider, B., Marcone, C., Smart, C.D. and Kirkpatrick, B.C. 1998. Detection and identification of fruit tree phytoplasmas by PCR amplification of ribosomal and non ribosomal DNA. p.56-66. In: C. Manceau, and J. Spak (eds.), New Technologies to improve Phytodiagnosis: Advances in the Detection of Plant Pathogens by Polymerase Chain Reaction. Office of the Official Publication of the European Community, Luxembourg.

Smith, I.M., McNamara, D.G., Scott, P.R. and Harris, K.M. 1992. Apple proliferation MLO. In: Quarantine pests for Europe. CAB International, Wallingford, UK (Updated on February 15, 2006).

Tedeschi, R., Bosco, D. and Alma, A. 2002. Population dynamics of Cacopsylla melanoneura (Homoptera: Psyllidae), as a vector of apple proliferation in north western Italy. J. Econ. Entomol. 95:544-551.

Torres, E., Bertolini, E., Cambra, M., Monton, C. and Martin, M.P. 2005. Real-time PCR for simultaneous and quantitative detection of quarantine phytoplasmas from apple proliferation (16SrX) group. Mol. Cell. Probes 19:334-340.

Zhang, Y., Uyemoto, J.K. and Kirkpatrick, B.C. 1998. A small-scale procedure for extracting nucleic acids from woody plants infected with various phytopathogens for PCR assay. J. Virol. Methods 71:45-50.

\section{$\underline{\text { Tables }}$}

Table 1. Phytoplasma isolates and host plants from different localities examined in this study.

\begin{tabular}{lcc}
\hline Strain & Strain form & $\begin{array}{c}\text { Accession number or } \\
\text { geographical origin }\end{array}$ \\
\hline AT & periwinkle infected & Accession no. X68375 \\
AP15 & periwinkle infected & Accession no. AJ542541 \\
AT1/93 & periwinkle infected & Accession no. AJ542542 \\
AT5/93 & periwinkle infected & Dossenheim (Germany) \\
AT12/93 & periwinkle infected & Dossenheim (Germany) \\
AT1-Proliferation & apple infected & Lempdes (France) \\
AT1-No.2 & apple infected & Lempdes (France) \\
AP-N17 & apple infected & Lempdes (France) \\
AT1-IDARED & apple infected & Lempdes (France) \\
AT2-SO8D & apple infected & Lempdes (France) \\
ESFY1 & extracted DNA & Accession no. AJ542544 \\
ESFY2 & extracted DNA & Accession no. AJ542545 \\
ESFY & periwinkle infected & Dossenheim (Germany) \\
PD & extracted DNA & Accession no. AJ542543 \\
PD1 & periwinkle infected & Dossenheim (Germany) \\
EY (16SrV) & extracted DNA & Accession no. X68376 \\
\hline
\end{tabular}

${ }^{1}$ A strain of Elm Yellows Phytoplasma. 
Table 2. List of different primers and probes used for detection of phytoplasmas.

\begin{tabular}{ccc}
\hline Name & Sequence 5'-3' & Reference \\
\hline qAP-16S-F & CGAACGGGTGAGTAACACGTAA & Baric and Dalla-Via, 2004 \\
qAP-16S-R & CCAGTCTTAGCAGTCGTTTCCA & Baric and Dalla-Via, 2004 \\
AP5 & TCTTTTAATCTTCAACCATGGC & Jarausch et al., 1995 \\
AP4 & CCAATGTGTGAAATCTGTAG & Jarausch et al., 1995 \\
qAP-16S & FAM-TAACCTGCCTCTTAGACG-MGB & Baric and Dalla-Via, 2004 \\
AP-MGB & FAM-CTGCCTCTTAGACGAGG-MGB & Designed in this study \\
\hline
\end{tabular}

\section{Figures}

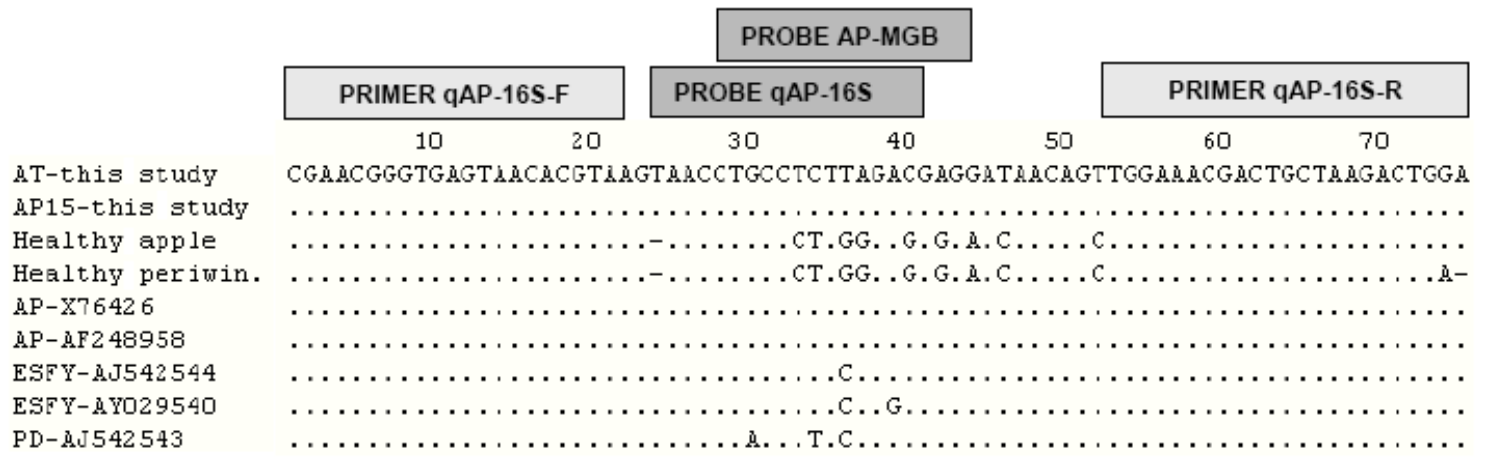

Fig. 1. Alignment comparison of a sequenced region of 16S rRNA gene in two strains of Apple Proliferation (AT and AP15) and two healthy samples (apple and periwinkle) with reference strain of AP, ESFY and PD. In sequence alignments, the dots mean as the same nucleotide with primary sequence and "-" means absence of nucleotide.
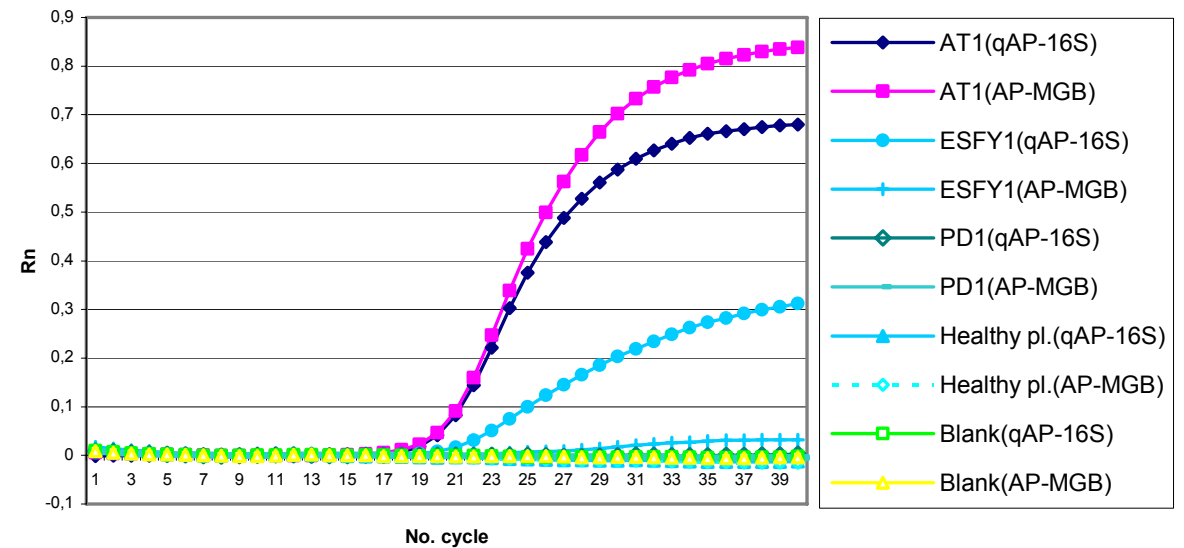

Fig. 2. Fluorescent intensity of amplification of different phytoplasma isolates obtained by real-time PCR with qAP-16S-F/R primers and qAP-16S and AP-MGB probes at $64^{\circ} \mathrm{C}$ as hybridization temperature. 
